\title{
Sobre A Tradução Em Prosa Comentada De Trechos Da Obra Midsummer Night And Other Tales In Verse, De John Masefield
}

\section{On An Annotated Translation In Prose Of Excerpts Of The Work Midsummer Night And Other Tales In Verse, By John Masefield}

Natalia Ferrigolli ${ }^{1}$

Lenita Maria Rimoli Pisetta**

\footnotetext{
${ }^{1}$ Natalia Ferrigolli: Bacharela e Licenciada em Letras Português e Inglês na FFLCH/USP.

E-mail: natalia.ferrigolli.campos@alumni.usp.br

* Lenita Maria Rimoli Pisetta: Professora de Teoria e Prática de Tradução no Departamento de Letras Modernas, FFLCH/USP. E-mail: lenitarimolip@usp.br

TradTerm, São Paulo, v.38, fevereiro/2021, p. 91-115

Número Especial - III JOTA 
Resumo: Esta pesquisa almejou cooperar com a temática dos estudos arturianos, apresentando a tradução em prosa de excertos da obra Midsummer Night and Other Tales in Verse (1928), do poeta John Masefield (1878-1967), ainda pouco conhecido no Brasil. Segundo nossas pesquisas, esta é a primeira tradução para o português brasileiro dessa obra, da qual foram selecionados episódios-chave, apresentados de acordo com sua ordem de aparição no livro. Foram escolhidos dois do total de vinte e dois episódios, incluindo aquele que dá o nome à obra. Optou-se por realizar a tradução em prosa por se tratar de uma pesquisa inicial e para que o texto ficasse mais acessível aos leitores da atualidade.

Palavras-chave: Midsummer Night and Other Tales in Verse; John Masefield; Lendas arturianas; Tradução comentada em prosa; Tradução literária.

Abstract: This research has aimed to contribute to the theme of Arthurian studies, introducing the annotated prose translation of excerpts of the work Midsummer Night and Other Tales in Verse (1928), by British poet John Masefield (1878-1967), who is still little known in Brazil. According to our research, this is the first translation into Brazilian Portuguese of this work, from which have been selected key-episodes, which are presented in the same order as they appear in the book. Two out of twenty-two episodes were selected, including the one that gives the title to the work. The option for a prose translation is due to the fact that this is an initial research and also aimed to present a more accessible text to nowadays readers.

Keywords: Midsummer Night and Other Tales in Verse; John Masefield; Arthurian legends, Annotated translation in prose; Literary translation.

TradTerm, São Paulo, v.38, fevereiro/2021, p. 91-115

Número Especial - III JOTA

www.revistas.usp.br/tradterm 


\section{Introdução}

0 presente artigo é o fruto de um trabalho de Iniciação Científica realizado durante o ano de 2018 e 2019 cujo principal objetivo foi apresentar a obra Midsummer Night and Other Tales in Verse, do poeta britânico John Masefield, por meio de uma tradução comentada em prosa de excertos escolhidos. Acompanham a tradução comentários sobre as principais dificuldades e decisões, referentes ao tratamento dos nomes próprios e à diferenciação das vozes narrativas, dependendo do episódio. Por exemplo, enquanto a terceira pessoa do singular domina o discurso de grande parte da narração descritiva dos episódios selecionados, a fim de relatar as ações de cada personagem, há momentos específicos em que o narrador aparece em primeira pessoa como numa espécie de metalinguagem. Além disso, introduzse o discurso direto das personagens de modo oral e dramático, principalmente no episódio que dá nome à obra.

A decisão pela tradução em prosa se deveu a vários fatores, sendo o principal deles atrair um número maior de leitores, que provavelmente incluirá pessoas jovens que se interessam pelas lendas arturianas (histórias em torno do Rei Artur e os Cavaleiros da Távola Redonda), mas talvez ainda não tenham a bagagem requisitada para ler as narrativas poéticas.

Com temáticas sobre honra, coragem, aventura, igualdade, companheirismo e alguns elementos fantasiosos típicos das novelas de cavalaria, a poesia de Masefield também apresenta embates de sua época associados à guerra e aos conflitos do indivíduo moderno que busca respostas nas tradições nacionais para os problemas mundiais.

\subsection{John Masefield e sua obra em sua época}

Quanto ao autor da obra, Masefield (1878-1967) foi poeta laureado (Poet Laureate) de 1930 até sua morte. Tal título se refere a um cargo existente na cultura anglo-saxônica, designado oficialmente pelo chefe de governo do país (ou de um determinado estado ou território) e cuja durabilidade não é constante.

TradTerm, São Paulo, v.38, fevereiro/2021, p. 91-115

Número Especial - III JOTA

www.revistas.usp.br/tradterm 
Pertencente ao movimento georgiano de poesia (YATES 2005), o poeta é de um modo geral mais tradicional no aspecto da forma poética, uma vez que pode ser considerado como 'antiquado' pelo teórico Rob Gossedge (2007: 250).

De um modo geral, sua obra Misummer Night and Other Tales in Verse faz parte da escola literária modernista inglesa, retomando tradições cavaleirescas enquanto lida com a violência do período entreguerras. É possível encontrar essa brutalidade sanguinária dentro dos episódios, inclusive pela experiência de Masefield dentro do exército (Gossedge 2007: 108). No texto, a forma dominante é a épica, embora a lírica e a dramática também apareçam.

Para Gossedge, a obra mais importante de Masefield no campo arturiano é Midsummer Night and Other Tales in Verse. Seu eclético número de fontes combinou mitologia clássica e nortenha, pesquisa histórica, referências maloryanas e antigos materiais galeses, assim como a própria imaginação do escritor (GOSSEDGE 2007: 220-222).

\subsection{Sobre a tradução}

Esta tradução oferece aos leitores a recriação da poesia de Masefield na forma de prosa, mas valendo-se de elementos poéticos. Dessa maneira, os comentários complementam a leitura da tradução propriamente dita, considerando que a obra dele já é uma releitura arturiana.

Em suma, o livro do poeta aborda as aventuras do Rei Artur desde os eventos que acarretaram o seu nascimento, vistos a partir de duas perspectivas: a primeira sendo uma variação idealizada de amor criada por Masefield em que os pais do Rei Artur têm uma paixão proibida; a segunda, a lenda popular em que o Rei Úter, pela magia de Merlin, engana Igerna ao tomar a aparência de seu marido e a engravidar. Depois, o livro segue episódios no estilo de saga em que o Rei Artur deve se mostrar herói e são típicos da lenda: o adultério da Rainha Ginevra, sendo o seu julgamento narrado em dois pontos de vista também; as tramoias do bastardo Mórdred, o responsável pela queda do reino, filho incestuoso do Rei Artur com sua tia

TradTerm, São Paulo, v.38, fevereiro/2021, p. 91-115

Número Especial - III JOTA

www.revistas.usp.br/tradterm 
Morgause, Rainha das Órcadas, entre outros temas que ora seguem a tradição, ora são inspirações de Masefield.

Em seu contexto histórico e no da literatura inglesa, Masefield queria, por meio da recriação da novela de cavalaria influenciada principalmente por Lord Alfred Tennyson (1809-1892), trazer de volta os tempos heroicos da Inglaterra. Certamente, um ponto de vista patriota: construir uma epopeia inglesa preocupada com a Primeira Guerra Mundial (GOSSEDGE 2007: 228-229). Em meio a tantos autores que recorreram ao passado glorioso arturiano para refletir o presente, eles retomam a epopeia de um modo diverso à teoria de Lukács, que associa o romance a uma forma épica na modernidade burguesa. Autores arturianos como Masefield recriam a épica retomando a poesia a partir dos ideais cavaleirescos, mas influenciados por seus contextos modernos (LUKÁCS 1999: 195).

Em seguida, estão os dois episódios que foram traduzidos na ordem original em que aparecem no índice de Masefield, com a sua respectiva versão ao lado direito:
1) THE BEGETTING OF ARTHUR;
1) A CONCEPÇÃO DE ARTUR;
8) MIDSUMMER NIGHT;
8) UMA NOITE DE VERÃO;

Apesar de o oitavo episódio sugerir o solstício, pretendeu-se recuperar, ao traduzir o título, a inspiração que o autor teve na comédia de Shakespeare A Midsummer Night's Dream (Sonho de uma Noite de Verão) (SHAKESPEARE 1594-1595: 7).

Nos dois episódios escolhidos, há duas linhas narrativas: uma predecessora à do Rei Artur, sobre o romance de seus pais, o Rei Úter e a Princesa Igerna; outra a respeito do narrador moderno que encontra as personagens típicas do mundo arturiano sob um encanto na noite de solstício de verão. (GOSSEDGE 2007: 225).

TradTerm, São Paulo, v.38, fevereiro/2021, p. 91-115

Número Especial - III JOTA

www.revistas.usp.br/tradterm 


\section{Metodologia}

Para a tradução, ambos os episódios foram selecionados com base em sua importância para os acontecimentos em peso da obra em um todo: os eventos anteriores ao nascimento do Rei Artur, cruciais para definir não só sua ascensão como sua ruína e o episódio que intitula a obra.

A edição de Midsummer Night and Other Tales in Verse utilizada para esta tradução foi publicada em 1928, embora Gossedge adote como data de publicação da obra 1927 (2007: 108).

Nesta pesquisa, os episódios presentes traduzidos consistem na metade do primeiro episódio e no oitavo episódio. 0 excerto inicial é repleto de imagens poéticas do ponto de vista épico em contraste com o episódio seguinte escolhido para comparação, o oitavo, cujo foco narrativo ou voz lírica oscila pelos três gêneros literários descritos por Rosenfeld (1986: 15).

Escolhemos esses dois para o artigo porque o primeiro explica as origens do Rei Artur, dando um panorama que situa o leitor dentro da obra. Já o oitavo foi selecionado por causa de sua riqueza tanto em aspectos formais como em conteúdo: o foco narrativo em primeira pessoa, as personagens do Rei Artur, a Rainha Ginevra, o Cavaleiro Lancelote, o Traidor Mórdred etc., a atmosfera fantasiosa, entre outros fatores.

- Primeiro episódio: "The Begetting of Arthur/A Concepção de Artur:

Nesse episódio, conta-se como o Rei Artur foi gerado. O Rei Úter apaixona-se pela Princesa Igerna, filha do Rei Mérquion da Cornualha, já prometida para o barão Breuse. Os dois fogem e, após uma noite de núpcias na floresta, os homens do Rei Mérquion os encontram e matam o Rei Úter antes do nascimento do Rei Artur.

A tradução vai até o ponto da narrativa em que a Princesa Elaine pede a ajuda do Rei Úter para resgatar sua irmã Igerna do Castelo de Tintagel e de seu casamento com o Barão Breuse. Os dois, então, começam a planejar o sequestro da futura mãe do Rei Artur e fuga com o Rei Úter. Ainda que não seja mostrado neste artigo, na pesquisa há a tradução de outro episódio em que a versão mais conhecida da concepção do Rei Artur ocorre: O Rei Úter

TradTerm, São Paulo, v.38, fevereiro/2021, p. 91-115

Número Especial - III JOTA

www.revistas.usp.br/tradterm 
manda que o mago Merlin o transforme no marido de Igerna para que ela se deite com ele, gerando o príncipe Pendragon.

- Oitavo episódio: “Midsummer Night”/Uma Noite de Verão:

Neste trecho, a narrativa fica mais lírica e dramática, abandonando em certa medida os traços épicos dos outros episódios. Há também a presença de metalinguagem quando o eu lírico fala do seu próprio fazer poético. Esta voz lírica ou narrador atua como uma testemunha quando observa as personagens arturianas interagirem, apresentando um quê fantasioso e inusitado ao livro.

Quanto aos comentários, eles foram feitos introdutoriamente e em notas de rodapé e dizem respeito principalmente às dificuldades encontradas e explicações necessárias para situar a leitura.

\section{Tradução}

\section{ORIGINAL MIDSUMMER NIGHT AND OTHER TALES IN VERSE}

TO MY WIFE

\author{
TRADUÇ̃̃O \\ UMA NOITE DE VERÃO
}

PARA

MINHA ESPOSA

\section{THE BEGETTING OF ARTHUR}

\section{A CONCEPÇÃO DE ARTUR}

\section{RESUMO DE A CONCEPÇÃO DE ARTUR:}

O Rei Úter tenta se aproximar da Princesa Igerna, filha do Rei Mérquion, que já está prometida para o Barão Breuse. O Rei da Cornualha é contra a proposta do Rei Úter, que foge com a Princesa Igerna do Castelo de Tintagel e os dois consumam seu amor na floresta. Isto resulta na morte do Rei Úter e na gravidez da Princesa que gera o futuro Rei Artur. 


\subsection{Comentários introdutórios:}

Neste episódio, há um duplo conflito, de ordem política e afetiva, uma vez que o Rei Úter quer iniciar uma aliança de reis para lutar contra a invasão dos saxões e, ao recorrer ao Rei Mérquion da Cornualha, este se recusa a se juntar à sua causa, em razão da ascendência romana daquele. Ademais, o Rei Úter se apaixona pela Princesa Igerna. Ela tem outras duas irmãs, a Princesa Elaine e a Rainha Morgause.

Em relação aos desafios a se apontar, os aspectos estrangeiros e arcaicos dos nomes das personagens certamente são algo que distanciaria os leitores da língua portuguesa se fossem deixados em suas versões originais. Por isso, decidiu-se traduzi-los com base em alguns dos nomes presentes no livro A Demanda do Santo Graal organizado por Heitor Megale (2008: 12) e realizar algumas adaptações. Megale é atualmente professor de filologia e língua portuguesa da Universidade de São Paulo. Editou a primeira versão no Brasil de A Demanda do Santo Graal, que aborda as lendas arturianas. Conforme a definição de Adriana Zierer, a obra tem origem francesa: "uma novela de cavalaria produzida na França no século XIII num período de prosificação e cristianização da Matéria da Bretanha” (ZIERER 2013: 1).

Também se empregou algumas romanizações de Geoffrey of Monmouth, presentes em Historia Regum Britanniae, por serem, linguisticamente, próximas ao português. Como ocorre com o caso do nome Igerna (c. 1136: 141), a mãe do Rei Artur. Ele tem várias versões ao longo da obra de Masefield: Ygern, Ygerna, Ygrain e Ygraine. O poeta parece selecionar cada versão de acordo com a necessidade da métrica em cada contexto poético. A obra de Monmouth foi, de acordo com a tese de Dircilene Gonçalves, uma narrativa composta em um todo de doze livros em que "é criada uma origem mitológica para o povo britânico" (2015: 71).

O autor configura uma transição entre a oralidade e a escrita das novelas de cavalaria: "ao mesclar dados históricos comprovados com pensamentos e sentimentos notadamente ficcionais porque impossíveis de serem registrados, ele engendra uma história romantizada". Assim, Monmouth situa seu texto "numa zona de intersecção de história e ficção e lançando as

TradTerm, São Paulo, v.38, fevereiro/2021, p. 91-115

Número Especial - III JOTA

www.revistas.usp.br/tradterm 
bases para o que viria a ser a novela de cavalaria. [...] ele claramente escreve para ser lido, não declamado" (GONÇALVES 2015: 74).

O nome do Rei Mérquion, a título de exemplo, foi bem difícil de ser traduzido. Na pesquisa, não foi possível encontrar informações sobre sua pronúncia em inglês. Optou-se por transformar graficamente em "Mérquion" na tradução, acentuando e demarcando o fonema oclusivo velar /k/. Também não foram encontradas fontes confiáveis durante a pesquisa de variações romanizadas do nome, escolhendo-se adaptar o mais próximo da fonética anglo-saxônica portanto.

Já os pronomes escolhidos para tratar o receptor / os receptores do discurso são a segunda pessoa do singular e do plural, assim como os pronomes possessivos respectivos, a fim de deixar o texto mais verossímil e em concordância com a língua de chegada a partir da língua de partida.

\subsection{Tradução:}

UTHER, the Prince, succeeding to the post Of Red Pendragon, or Anointed Chief

Of all the Kings in Britain, saw with grief How jealousy and spite

King against King, let in the heathen host, Who, coming in their hundreds, found a land Of warring Kingdoms owning no command, And therefore sackt, uncheckt, from Tyne to Wight.

\begin{abstract}
Úter, o Príncipe ${ }^{2}$, ascendendo ao posto de Chefe-Dragão Vermelho ${ }^{3}$, ou Comandante Ungido de todos os Reis da Grã-Bretanha ${ }^{4}$, constatou com profunda tristeza como o ciúme e rancor de Rei contra Rei abriram as portas ao exército pagão que, chegando às centenas, encontrou uma terra de reinos em guerra sem poder de comando e,
\end{abstract}

\footnotetext{
${ }^{2}$ Ora Masefield refere-se a Úter como Rei, ora como Príncipe, a partir do momento que ele é ungido como Pendragon, passaremos a nos referir a ele como Rei.

3 De acordo com a definição do MICHAELIS, o termo faz referência a um "chefe supremo" (entre os antigos bretões).

4 Para a escolha do termo Grã-Bretanha na tradução de 'Britain', houve um estudo comparando outros termos parecidos para ver qual se encaixava melhor: GRÃ-BRETANHA: Maior parte territorial do Reino Unido, correspondendo à ilha que contém os atuais países: Inglaterra, Escócia e País de Gales. Seu emprego remonta a 1603 d.C., "quando James VI da Escócia se tornou James I da Inglaterra (incluindo o País de Gales)" (THEFREEDICTIONARY). De acordo com Megale, as lendas arturianas, surgiram durante a Idade Média, ou seja, do séc. VIII ao séc. XII d.C. (MEGALE 2008: 12); BRETANHA: Parte do território que hoje pertence à França (GONÇALVES 2015: 71); BRITÂNIA: Província romana que se localizava ao centro-sul da ilha da Grã-Bretanha. (BEVAN 2010); ÁLBION: Designação poética da região da Inglaterra ou da Grã-Bretanha. Na tradução, optou-se por traduzir o termo ‘Britain’ por Grã-Bretanha, a fim de que os leitores da atualidade compreendam bem a noção geográfica do território a que Masefield faz referência, mesmo que as lendas arturianas sejam mais antigas do que o emprego do termo (THEFREEDICTIONARY).
}

TradTerm, São Paulo, v.38, fevereiro/2021, p. 91-115

Número Especial - III JOTA www.revistas.usp.br/tradterm 
portanto, saqueou, desenfreado, todo o território.

So when he took the purple he began,

Among his friends, to build a league of Kings:

Iddoc of Kent, among the Easterlings;

The Orkney pirate, Lot;

Then, from the North, the golden hero, Ban;

And having these, he greatly longed to win

Old Merchyon, King of Cornwall rich in tin, Whose strength would bind the leaguers like a knot.

Assim que subiu ao trono, ele começou a construir uma liga de Reis entre seus amigos: Idoque de Câncio, entre os Orientais; Lote, o pirata Órcade; depois, Ban, do Norte, o herói de ouro. $\mathrm{E}$, contando com esses, ele queria muito conquistar o Velho Mérquion, Rei da Cornualha rica em estanho, cuja força uniria os aliados como um nó.

None loved King Merchyon: Prince Uther knew

That he was aged, savage, mean and grim; That baron Breuse, the Heartless, lived with him, Of all bad men the worst;

That in Tintagel, nest-rock ${ }^{5}$ of the mew, His daughters lived with him, the dark Ygraine, That moon of women; then the bright Elaine, And little Morgause, whom a witch had curst.
O Rei Mérquion não era amado: Úter sabia que ele era idoso, bárbaro, vil e repugnante; que o barão Breuse $^{6}$, o Cruel, vivia com ele, de todos os homens maus, o pior; que em Tintagel ${ }^{7}$, ninho rochoso das gaivotas, suas filhas também moravam, a morena lgerna, aquela lua das damas; também a radiante Elaine, e a pequena Morgause, a qual fora amaldiçoada por uma bruxa.

So, knowing that the urger of a cause Must urge the cause in person, Uther rode With Kol and Guy, to Merchyon's abode, And in Tintagel tower

Pled eloquently to him without pause, With all a young man's beauty, flusht and true; And as he pled, Ygerna watcht and knew That of all knights Prince Uther was the flower.

Dessa forma, sabendo que o defensor de uma causa deve defendê-la em pessoa, Úter cavalgou com Kol e Guy para a morada de Mérquion. $\mathrm{Na}$ torre de Tintagel, argumentou com ele, eloquente, sem titubear, com toda a beleza de um jovem, pujante e verdadeiro. Conforme ele argumentava, Igerna observava e percebia que, de todos os cavaleiros, o Príncipe Úter era a mais fina flor.

Then Merchyon answered, "I have heard your plea.

I will not mingle in remote affairs,

I can mind mine, let others manage theirs:

What can the East, or Wales,

Or all of northern Britain, mean to me?

No Cornish men shall bleed in the employ

Of you, or others like you, Roman boy.
Em seguida, Mérquion respondeu:

- Ouvi teu argumento. Não vou intervir em questões alheias, já cuido das minhas, que os outros cuidem das deles. 0 que pode significar para mim o Leste, Gales, ou o norte da GrãBretanha? 0 sangue de nenhum

\footnotetext{
${ }^{5}$ Esta expressão, por envolver dois substantivos, foi um pouco difícil de traduzir. Por fim, optou-se por transformar o termo "rock" em adjetivo, pois a ideia de ninho rochoso das gaivotas é uma perífrase do Castelo de Tintagel.

${ }^{6}$ Comparsa do Rei Mérquion, noivo da Princesa Igerna.

${ }^{7}$ Castelo em que mora a Princesa Igerna, mãe do Rei Artur, e sua família.
}

$$
\begin{gathered}
\text { TradTerm, São Paulo, v.38, fevereiro/2021, p. 91-115 } \\
\text { Número Especial - III JOTA } \\
\text { www.revistas.usp.br/tradterm }
\end{gathered}
$$




\begin{tabular}{|l|l|}
\hline Your schemes are childish and your fears are tales. & $\begin{array}{l}\text { homem da Cornualha deve ser } \\
\text { derramado por tua causa ou pela de } \\
\text { outros como tu, infante de Roma. } \\
\text { Teus planos são pueris e teus medos, } \\
\text { mentiras. }\end{array}$ \\
\hline
\end{tabular}

Or if not so, perhaps the Romans plan

To recommence their empire, for in truth

Taxes and tribute and conscripted youth

Are playthings dear to Rome.

But you, my Roman, come to the wrong man." So raging, wrapping close his scarlet cloak, He left the hall: Breuse, as he followed, spoke. "That was your answer, Uther; make for home."
Ou, senão isso, talvez os Romanos planejem recomeçar seu império, pois de fato, as taxas, tributos e o recrutamento de jovens são diversões caras aos romanos. Contudo, tu, meu Romano, recorres ao homem errado.

Então, cobrindo-se com a capa escarlate, o Rei Mérquion deixou o saguão. Conforme o seguia, Breuse falou:

- Eis tua resposta, Úter; volta para casa.
Breuse and his sworders followed Merchyon out, Uther had neither welcome nor farewell, Comfort, nor rest, nor water from the well, Nor food for man or horse.

He stood a moment, betwixt rage and doubt. "Sir," said Ygerna, coming from her place, "Father is old: forgive his want of grace. To-morrow he'll be broken with remorse."
Breuse e seus espadachins escoltaram Mérquion. Úter não era bem-vindo, nem digno de despedida, conforto, descanso, tampouco água do poço, nem comida para os homens nem os cavalos. Ele parou por um momento, entre a raiva e a dúvida.

- Senhor - disse Igerna, vindo de seu lugar. - Meu pai é velho: perdoa sua carência de polidez. Amanhã ele estará arruinado pelo remorso.
Then Uther for the first time saw Ygern ${ }^{8}$; And at her voice and at her wistful glance, Love stabbed his spirit with her beauty's lance; While she, made faint with love, Felt the hot blush upon her temples burn. Love to both startled mortals made it known That each was other's to the inward bone Through some old passion in the stars above.
Foi então que Úter, pela primeira vez, viu Igerna ${ }^{9}$. Diante daquela voz e daquele olhar melancólico, seu espírito foi apunhalado pelo arpão da beleza dela, enquanto Igerna, tímida por causa do amor, sentiu as têmporas arderem. 0 amor comunicou aos dois assustados mortais que um pertencia ao outro até a essência por meio de uma paixão antiga escrita nas estrelas.
As in October when the Channel mist

With silent swathes of greyness hides the sea Until none knows where land or water be, And suddenly a blast
Como em outubro, quando a névoa do canal esconde o mar com faixas de cinza até ninguém saber onde é terra ou água, e de repente, uma

\footnotetext{
${ }^{8}$ Outro modo de chamar a mãe do Rei Artur na versão original.

${ }^{9}$ Parágrafo em que o Rei Úter se apaixona pela Princesa Igerna, repleto de metáforas que se seguem.
TradTerm, São Paulo, v.38, fevereiro/2021, p. 91-115
Número Especial - III JOTA www.revistas.usp.br/tradterm


Scatters and shreds the vapours into twist

And all is glorious sunlight, wind and foam, Through which a towering ship comes striding home, Spray to the rail, with colours at her mast; rajada de vento dispersa e rasga 0 nevoeiro em uma guinada e tudo se torna a gloriosa luz do sol, brisa e escuma, através da qual um imponente navio vem para casa, espuma no parapeito, bandeira no mastro. ${ }^{10}$
Or as, in mild Novembers, when the pack Whimpers in covert and the hunters wait, Under slow-dropping oak-leaves falling late, Making no sound at all, And suddenly the fox with hollow back Breaks, with a crying leader at his brush, And all those riders gathered for the rush Surge for the fence, not heeding any call,
Ou como, em novembros amenos, quando o bando de raposas geme no esconderijo e os caçadores esperam, sob folhas lentas e tardias a quedar do carvalho, sem emitir qualquer ruído, e subitamente, a raposa surge encolhida, com um líder gritando em seu encalço, e todos aqueles cavaleiros reunidos para a caçada vêm à frente, sem precisar de qualquer chamado. ${ }^{11}$
So, to those two, the greyness and delay Of all their lives' endeavour and employ, The hollowness which they had counted joy, The hopes which had been dear Until that instant, all were swept away; They were alone upon an ocean shore Where nothing meant nor mattered any more Save their two souls and being without fear.
Assim, para ambos, o cinza e a demora ${ }^{12}$ de todo o empenho e dever de suas vidas, o vazio que haviam considerado alegria, as esperanças que tinham sido estimadas até aquele instante, tudo foi varrido; eles estavam sozinhos numa praia, onde nada mais tinha significado nem importância, a não ser suas almas e não ter medo.
"O princess," he began, “O dark-haired Queen, 0 moon of women, we have met again, We who are one yet have been cut atwain To seek ourselves till now.

Whatever griefs are coming or have been, Love in his glory grants us to make whole Our bleeding portions of divided soul That our last dying sundered with the plough."
- Ó princesa, - começou ele -, Ó Rainha dos cabelos escuros, ó lua das damas, encontramo-nos novamente, nós que somos um, fomos, porém, partidos em dois para nos procurarmos até agora. Quaisquer que sejam os lutos por vir ou de outrora, o amor, em sua glória, dá a permissão de inteirarmos as partes sofridas de nossa dividida alma que a nossa última morte separou com o arado.

\footnotetext{
${ }^{10}$ Neste trecho, encontra-se uma metáfora de como o Rei Úter e a Princesa Igerna se sentiram ao se apaixonarem à primeira vista, uma espécie de desconhecimento em que ambos viviam até se conhecerem enfim e o dia, antes nublado, se abrir e a descrição ficar mais complexa, deixando a tradução mais rica.

11 No fragmento acima, foi difícil compreender a metáfora da caça de raposas e da expectativa que ela gera, pois não é um costume cultural brasileiro. A parte de um líder que parte no encalço do animal não estava muito clara e essas duas imagens das estrofes foram desafiadoras para traduzir. É interessante como Masefield retoma ambas as sensações na estrofe seguinte.

12 É curioso como o autor retoma as duas estrofes anteriores, mencionando as sensações descritas nelas sintetizadas: "o cinza e a demora".

TradTerm, São Paulo, v.38, fevereiro/2021, p. 91-115

Número Especial - III JOTA www.revistas.usp.br/tradterm
} 
Then, being in the certainty of love,

That cannot doubt, however it be blind,

Those two young lovers plighted mind to mind,

And straightway told the King;

Who cried, "A pretty plot, by Heaven above.

Since I, as the King, refused to be allied, You think to win my power through a bride Whose loving father grants her everything.
Então, tendo a certeza do amor, que não duvida, apesar de ser cego, aqueles dois jovens amantes juraram eterno vínculo, e imediatamente, contaram ao Rei; que exclamou:

- Céus, que bela trama. Já que eu, como Rei, recusei ser teu aliado, tu achas que ganharás meu poder por meio de uma noiva cujo carinhoso pai the concede tudo.
Not so, my Roman, for I see your plot.

Keep to your own princesses; she shall wed

My Breuse, who has no Latin in his head,

And you shall go out shamed...

You sworders, make this loving swain less hot...

Set him ahorseback with his head for home.

And keep from Cornwall henceforth, man of

Rome,

Or Cornish hands will swiftly have you tamed."
- Nada disso, meu Romano, pois eu percebo tua trama. Guarda-te para tuas próprias princesas; ela deverá se casar com meu Breuse, que não possui nenhum sangue romano, e tu deves partir desonrado... Vós espadachins, deixai este amoroso pretendente menos apaixonado... Enviai-o à via de sua vivenda com vida. $E$, doravante, fica longe da Cornualha, homem de Roma, ou mãos Córnicas hão de amansar-te.
Then instantly, before Ygraine could plead, Or Uther answer, he was hustled forth (He and his Knights) and headed for the north, With orders not to turn.

Since three alone were helpless, they agreed To the tide's setting, but they rode in rage, Vowing to set King Merchyon in a cage Next Sarum Fair ${ }^{13}$, to suffer and to learn.

Logo em seguida, antes que lgerna
pudesse argumentar, ou Úter
responder, ele foi empurrado para a
frente (Ele e seus Cavaleiros) e
seguiram para o norte, proibidos de
retornar. Visto que os três sozinhos
eram impotentes, eles concordaram
com o rumo da maré, mas cavalgaram
com ira, jurando colocar o Rei
Mérquion na cadeia na Próxima Feira de
Sarum, para sofrer e aprender.

Contudo, depois do meio-dia, quando Úter parou para contemplar o Oeste, a partir da charneca, o lar de Igerna, lá, no pântano, ele divisou um cavaleiro vindo, negro contra o céu candente, galopando na direção dele. E, aproximando-se, eis que era Elaine, ansiosa, despenteada, Calling, "O Uther, help, or she will die...

13 Sarum era o antigo nome para Salisbúria, uma cidade inglesa. Cf. SARUM <https://www.thefreedictionary.com/Sarum> e SALISBURY <https://www.thefreedictionary.com/Salisbury>. Acesso em 16 de jan. 2021. O autor refere aqui que Úter e seus cavaleiros humilhariam o Rei Mérquion, colocando-o em uma gaiola na feira de Sarum, uma espécie de festival com vários costumes. Cf. FAIR <https://www.thefreedictionary.com/fair>. Acepção 2. Acesso em 16 de jan. 2021.

TradTerm, São Paulo, v.38, fevereiro/2021, p. 91-115

Número Especial - III JOTA www.revistas.usp.br/tradterm 


\begin{tabular}{|l|l|}
\hline & $\begin{array}{l}\text { montando com rédea firme, chamando: } \\
- \text { Ó Úter, ajuda, ou ela morrerá.... }\end{array}$ \\
\hline
\end{tabular}

Help us to-night, because my Father swears That Breuse shall wed Ygerna before Prime... Friend, can you help her in so little time? ... Not let her go to Breuse..."

"Men have plucked women out of dragons' lairs," King Uther said, "And I will pluck Ygraine. $O$ Rose in briars difficult to gain, Lighten my mind with stratagems to use."
Ajuda-nos esta noite, porque meu pai promete que Breuse casará com Igerna antes da aurora... Amigo, podes ajudála em tão pouco tempo?... Não a deixar ir ao Breuse...

- Homens resgataram mulheres de covis de dragões - o Rei Úter disse. - E assim resgatarei Igerna. Ó Rosa, em arbustos espinhosos difícil de conquistar, ilumina minha mente com estratagemas eficazes.
Then, having thought, he said, "This seems a chance. Your porter's old: suppose I climb the rock, Dresst like the King your father, and then knock At midnight on the door.

He, being old and drowsy, may but glance, Think me your father, bow, and open gates, Then, when I bring Ygern from where she waits, He may unfasten for me as before.
Então, após pensar, ele declarou:

- Esta parece uma chance. Teu porteiro é idoso: supõe que eu escale a rocha, disfarçado como el-Rei, teu pai, e, em seguida, bata na porta à meia-noite. Ele, sendo velho e estando sonolento, pode apenas olhar de relance, achar que sou teu pai, cumprimentar e abrir os portões, depois, quando eu trouxer Igerna de onde ela espera, ele pode abrir o portão para mim como fez antes.
It is worth trying, for, if it succeed, Ygern and I will be beyond the wall; And I can see no other chance at all Of saving her to-night...

And if I save her, sister, as God speed, I swear to take her to the hermit's cell And marry her before we cross the fell, Making her Queen from Isis to the Wight.
- Vale a tentativa, pois, se formos exitosos, Igerna e eu estaremos além do muro; e eu não consigo ver nenhuma outra chance de salvá-la esta noite... E se eu o fizer, irmã, se Deus quiser, eu juro que a levarei ao eremitério e me casarei com ela antes de atravessarmos o outeiro, fazendo dela Rainha de todo o território.
You, Kol, and Guy, arrange for horse-relays, From here to where King Merchyon's country ends; Swift horses, mind. About it: gallop, friends: And if the luck be fair, We'll meet again in Sarum in three days. Sister, be ready when the moon goes west. The hermit knows me, he is Bran the Blest, He will assist us: have the horses there.

$* * *$
- Vós, Kol, e Guy, arranjai cavalos para revezarmos, daqui até onde o país do Rei Mérquion termina; cavalos velozes, prestai atenção. Falando nisso: galopai, amigos: e se a sorte for justa, nós nos encontraremos novamente em Sarum daqui a três dias. Irmã, prepara-te quando a lua for para o oeste. 0 eremita me conhece, ele é Bran, o Abençoado, ele auxiliar-nos-á: leva os cavalos

TradTerm, São Paulo, v.38, fevereiro/2021, p. 91-115

Número Especial - III JOTA

www.revistas.usp.br/tradterm 


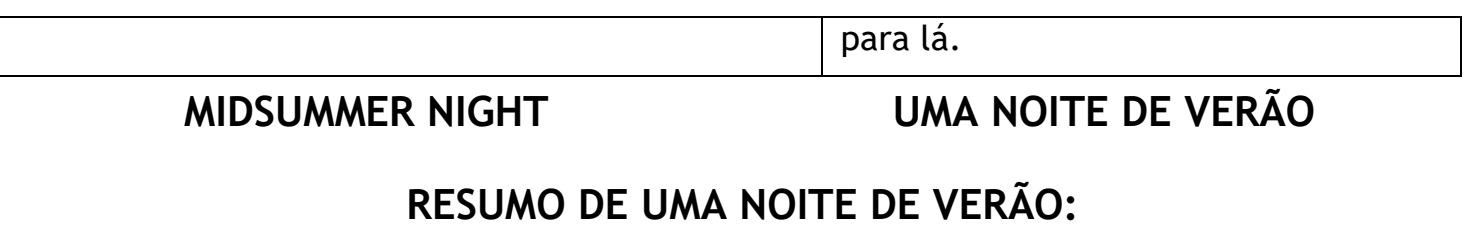

$\mathrm{Na}$ noite de solstício de verão, o narrador em uma atmosfera surreal encontra uma passagem secreta para uma espécie de salão escondido, guardado por um encanto em que as personagens arturianas estão petrificadas e despertam. Em um discurso confessional, cada uma assume sua culpa pela queda do reino, quase como uma forma de redenção (GOSSEDGE 2007: 226).

\subsubsection{Comentários introdutórios}

Neste episódio, o foco narrativo muda para a primeira pessoa e, depois, o narrador se transforma em uma testemunha de um texto em diálogo dramático das personagens arturianas, ou seja, as mudanças estilísticas interferem no processo de tradução. Simultaneamente, Masefield consegue passar da épica, quando narra na terceira pessoa do singular, para a lírica, neste episódio, e até por aspectos dramáticos com as falas que o narrador e 0 leitor assistem como testemunhas das personagens arturianas.

Na tradução da parte lírica, a descrição é mais repleta de adjetivos e de detalhes; na épica, de verbos e ações das personagens; e no discurso dramático, as personagens assumem longas falas, fazendo a tradução assumir, assim, facetas distintas. Vale ressaltar que, neste episódio, não há, no quesito do vocabulário, tanto a presença de arcaísmos como se nota nos outros episódios. No início do episódio, em que o narrador está próximo a um vale, ele faz uma descrição onírica do lugar em que está, das criaturas que o cercam, que precedem a magia que está prestes a acontecer.

Assim, o narrador, cansado de narrar, traz a metalinguagem junto com um vocabulário descritivo que é exótico aos leitores brasileiros.

\subsubsection{Sobre as personagens}

A respeito da Princesa Gineva e da Rainha Ginevra, que são irmãs: aquela, amante e cúmplice do Cavaleiro Mórdred, esta, sendo a rainha casada

TradTerm, São Paulo, v.38, fevereiro/2021, p. 91-115

Número Especial - III JOTA

www.revistas.usp.br/tradterm 
com o Rei Artur e a amante proibida do Cavaleiro Lancelote, herdeiro do reino. A Rainha Ginevra é assassinada pela própria irmã. Foi bem difícil encontrar uma tradução para o nome "Gwenivach” (Gwenhwy-fach, do galês) que é semelhante a “Gwenivere” (Gwenhwy-fawr, do galês) (CoLLINs 2004).

Já o Cavaleiro Mórdred é filho bastardo do Rei Artur, fruto da união de sua tia Morgause com ele. A Rainha Morgause é a filha caçula do Rei Mérquion e irmã mais nova da Princesa Igerna, mãe do Rei Artur. Amaldiçoada por uma bruxa, seu destino não é menos sombrio: ela é sequestrada ainda pequena pelo capitão Lote, um preço alto a se pagar pela sua curiosidade em observar os piratas de perto. Ele a leva para as Órcadas e faz dela sua rainha muito cedo. Depois, a Rainha Morgause visita a corte do Rei Artur para descobrir seus planos de batalha e o seduz, dando origem ao bastardo incestuoso Mórdred, rival do reino. Tais acontecimentos ocorrem nos episódios: "The Taking of Morgause" e "The Begetting of Modred".

Enquanto isso, Lancelote é primo do Rei Artur e seu herdeiro. Ao mesmo tempo, amante da adúltera Rainha Ginevra, esposa de sua majestade. Como o Príncipe Órcade Mórdred quer o trono, ele não hesita em conspirar contra o Cavaleiro Lancelote e a Rainha Ginevra.

\begin{tabular}{|l|l|}
\hline MIDSUMMER night had fallen in full moon, & $\begin{array}{l}\text { A noite de solstício de verão caiu com } \\
\text { a lua cheia, portanto, cansado do } \\
\text { So, being weary of my ancient tale, }\end{array}$ \\
I turned into the night, & $\begin{array}{l}\text { meu antigo conto, voltei-me para a } \\
\text { noite, ao longo da velha estrada que } \\
\text { vinha do vale. O terreno turvava-se } \\
\text { The downland dimmed before me, dune on dune, } \\
\text { Pale dogrose buds about me shed their scent; } \\
\text { The startled peewits glimmered as they went, } \\
\text { The moonlight made the earth and heaven white; } ; \\
\text { The heaven and earth together uttered June. }\end{array}$ \\
$\begin{array}{ll}\text { irradiavam seu perfume ao meu } \\
\text { redor; os abibes assustados } \\
\text { bruxuleavam conforme partiam, o } \\
\text { luar deixava a terra e o paraíso alvos; } \\
\text { o paraíso e a terra juntos anunciavam } \\
\text { junho. }\end{array}$ \\
\hline
\end{tabular}

\footnotetext{
So perfect was the beauty, that the air Was like immortal presence thrilling all The downland with deep life; Presences communed in the white owl's call; The rampart of the hill-top stood up bare, High on the windy hill a brightness shone -
}

Era tão perfeita a beleza, que o ar era
como uma presença imortal
entusiasmando todo o vale com intensa
vida; presenças comungavam no
chamado da coruja branca; a encosta
do topo do morro assomava nua, do

TradTerm, São Paulo, v.38, fevereiro/2021, p. 91-115

Número Especial - III JOTA www.revistas.usp.br/tradterm 
I wondered whose, since shepherd-men had gone Homeward a long time since to food and wife; Yet brightness shone, as from a lantern there. alto da colina envolta em vento, emitia-se uma claridade - eu me perguntei qual seria sua origem, já que os pastores haviam ido para casa há um bom tempo para encontrarem suas mulheres e comerem seu jantar; ainda assim, emitia-se claridade, como se fosse de uma lanterna ali.
Then, as the valley belfries chimed the hour, I thought: "On summer nights King Arthur's door, By yonder sarsens shut, Is said to open to a corridor Hewn far within the hill to Arthur's bower, Where he and Gwenivere, with all the tale Of captains toughened by the weight of mail, Bide in a hall within the limestone cut: That is the doorway, this is Arthur's hour."
Então, enquanto os campanários da baixada batiam as horas, eu pensei:

- Em noites de verão, dizem que a porta do Rei Artur, cerrada por aqueles blocos de arenito, leva a um corredor escavado bem no íntimo da colina até o caramanchão de Artur, onde ele e Ginevra, com toda a horda de capitães calejados pelo peso da armadura, residem em um salão aberto dentro do calcário: eis a entrada, esta é a hora de Artur.

\section{So, pressing near, behold, a door was wide}

Flung open on the steepness of the hill, Showing a lighted shaft.

A footlift fox was paused upon the sill; Eyes gleaming green, he fled. I stepped inside. The passage led within all brightly lit, Deft limestone hewers' hands had fashioned it. Behind me (as I thought) the white owl laught. The lighted way before me was my guide.
Assim, aproximando-me, eis que uma porta estava totalmente escancarada na declividade da colina, revelando um iluminado feixe de luz. Uma raposa estacou na soleira da porta empoleirada; com os olhos verdes cintilando, ela fugiu. Eu adentrei. A passagem que conduzia ao interior estava brilhantemente luminosa, moldada por mãos hábeis de talhadores de calcário. Atrás de mim (como eu pensava) a coruja branca ria ${ }^{14}$. 0 caminho iluminado diante de mim era meu guia. ${ }^{15}$
Till deep within the hill, I reacht a hall Lit, but so vast that all aloft was dim. The chilvary below
Até que profundamente no interior da colina, eu cheguei a um salão luminoso, mas tão vasto que tudo era sombrio no

${ }^{14} \mathrm{O}$ autor se utiliza aqui de uma personificação que reforça a atmosfera onírica e surreal do texto.

${ }^{15}$ A raposa é uma figura bastante presente ao longo dos episódios. Sua primeira aparição ocorre no primeiro episódio, quando o escritor compara o amor do Rei Úter e da Princesa Igerna à caça de raposas. Houve uma pesquisa sobre esse símbolo, em outras obras sobre o Rei Artur e, aparentemente, é uma característica peculiar de Masefield, não tendo uma associação direta com o mito. Contudo, há ocorrências na literatura inglesa. Percebe-se, assim, a atmosfera fantasiosa através da personificação da raposa que se apoia sobre duas patas e da coruja que ri.

$$
\begin{gathered}
\text { TradTerm, São Paulo, v.38, fevereiro/2021, p. 91-115 } \\
\text { Número Especial - III JOTA } \\
\text { www.revistas.usp.br/tradterm }
\end{gathered}
$$


Sat at their table stirring not a limb.

Even as frost arrests the waterfall,

So had a power frozen that array,

There at the banquet of the holy day, Into such stillness that I could not know

If they were dead, or carved, or living all. alto. Os nobres abaixo sentados à mesa sem mover um músculo. Como o inverno imobiliza a cachoeira, assim também havia algum poder congelando aquele grupo naquela posição, lá no banquete do dia sagrado, em tal imobilidade que eu não poderia saber se eles estavam mortos, esculpidos, ou todos vivos.
Then, entering in, accustomed to the light, I marked them well: King Arthur, black and keen, Pale, eager, wise, intense;

Lime-blossom Gwenivere, the red-gold queen; Ban's son, the kingly, Lancelot the bright; Gawaine, Bors, Hector; all whom trumpets drew Up Badon at the falling of the dew: And over them there brooded the immense Helper of Spirit with immortal sight.
Em seguida, entrando, acostumado à luz, eu os distingui bem: Rei Artur, sombrio e incisivo, pálido, ávido, sábio e intenso; Ginevra, flor-delimão, a rainha acobreada; o filho de Ban, o nobre, Lancelote, o radiante; Galvão, Bóris, Heitor; a quem cornetas chamavam ao longo de Badon ao cair do orvalho: e ali sobre eles pairava o imenso Espírito ${ }^{16}$ Ajudante com visão imortal.
All was most silent in that cavern nave

Save a far water dripping, drop by drop, In some dark way of time.

Power had brought that Knighthood to a stop, Not even their ragged banners seemed to wave, No whisper stirred the muscle of a cheek, Yet all seemed waiting for the King to speak. Far, far below I heard the midnight chime, The valley bells that buried silence clave.
Tudo estava no mais completo silêncio naquela nave da caverna, a não ser por um gotejamento de água remoto, gota a gota, em algum curso obscuro do tempo. O poder tinha provocado uma interrupção para aquela Nobreza, nem mesmo seus rotos estandartes pareciam ondular, nenhum murmúrio movia um músculo de um rosto, sequer, porém todos pareciam estar aguardando o Rei falar. Abaixo, muito abaixo eu ouvi o badalar da meia-noite, os sinos do vale que aquele sepultado silêncio partiam.
Then, at that distant music Arthur stirred; His scarlet mantle quivered like a wing. Each, in his golden stall, Smiling a little, turned towards the King, Who from his throne of glory spoke this word:"Midsummer Night permits us to declare How Nature's sickle cut us from the air And made the splendor of our summer fall." Then one by one they answered as I heard.
Depois, com a música distante Artur se moveu; seu manto escarlate tremeu como uma asa. Cada um, em seu assento áureo, sorrindo brevemente, voltou-se para o Rei, que de seu trono de glória falou estas palavras:

- A noite de solstício de verão nos permite declarar como a foice da Natureza nos ceifou do ar e fez ruir o

$16 \mathrm{Na}$ introdução do texto de Dodds sobre Masefield, é interessante a ideia de que esses ajudantes possivelmente estão ligados com a noção de purificação (MASEFIELD 1994: 27 ).

$$
\begin{gathered}
\text { TradTerm, São Paulo, v.38, fevereiro/2021, p. 91-115 } \\
\text { Número Especial - III JOTA } \\
\text { www.revistas.usp.br/tradterm }
\end{gathered}
$$


esplendor do nosso verão.

Então, um a um, eles responderam, enquanto eu ouvia.

\begin{tabular}{|l|l|}
\hline \multicolumn{1}{|c|}{ KING ARTHUR: } & \multicolumn{1}{|c|}{ REI ARTUR $^{17}$ : } \\
I was the cause of the disastrous end... & Eu fui a causa do fim desastroso... Eu, \\
I in my early manhood sowed the seed & no começo de minha virilidade plantei \\
That made the Kingdom rend. & a semente que fez o Reino se \\
I begot Modred in my young man's greed. & despedaçar. Eu gerei Mórdred na \\
When the hot blood betrays us, who gives heed? & ganância da minha juventude. Quando \\
Morgause and I were lovers for a night, & o sangue quente nos trai, quem de \\
Not knowing how the fates had made us kin. & nós dá atenção? Morgause e eu fomos \\
So came the sword to smite, & amantes por uma noite, sem saber \\
So was the weapon whetted that made bleed: & como os fados tinham feito de nós \\
That young man's loving let the ruin in. & parentes. Assim, veio a espada para \\
& punir, assim foi afiada a arma que fez \\
& sangrar: o amor daquele jovem abriu \\
& as portas para a ruína. \\
\hline
\end{tabular}

\begin{tabular}{|l|l|}
\hline \multicolumn{1}{|c|}{ GWENIVERE: } & \multicolumn{1}{c|}{ GINEVRA: } \\
I, Gwenivere the Queen, destroyed the realm; & Eu, Ginevra, a Rainha, destruí o reino; \\
I, by my love of Lancelot, the Bright; & eu, pelo meu amor por Lancelote, o \\
Destiny being strong and mortals weak, & Radiante; com a força do Destino e a \\
And women loving as the summer night. & fraqueza dos mortais, e com o amor \\
When I was seized by Kolgrim Dragon Helm, & das mulheres como a noite de verão. \\
Lancelot saved me from the Dragon-break, & Quando eu fui capturada por Kolgrim, \\
Love for my saviour came to overwhelm. & Elmo de Dragão, Lancelote me salvou \\
& da gruta do Dragão, o amor pelo meu \\
salvador se tornou irresistível.
\end{tabular}

Too well I loved him, for my only son, Lacheu $^{18}$, was his, not Arthur's as men thought. I longed to see my lover's son the King; But Lacheu, riding into Wales, was caught By pirates near St. David's and undone... They killed my Lacheu there.

The primroses of spring,

Red with his blood, were scattered in his hair: Thereafter nothing mattered to me aught...

Muito eu o amava, pois meu único
filho, Laqueu, era dele, não de Artur
como os homens pensavam. Eu
ansiava por ver o filho do meu amante
se tornar o Rei; mas Laqueu,
cavalgando até Gales, foi apanhado
por piratas perto de St. David's e
aniquilado... Eles mataram meu
Laqueu lá... As prímulas da
primavera, vermelhas com o seu
sangue, foram espalhadas por seu
cabelo: depois disso nada mais teve
importância para mim.

Muito eu o amava, pois meu único filho, Laqueu, era dele, não de Artur como os homens pensavam. Eu ansiava por ver o filho do meu amante se tornar o Rei; mas Laqueu, cavalgando até Gales, foi apanhado por piratas perto de St. David's e aniquilado... Eles mataram meu Laqueu lá... As prímulas da primavera, vermelhas com o seu sangue, foram espalhadas por seu importância para mim.

${ }_{17}$ Os traços dramáticos estão nas falas de cada uma das personagens arturianas, de certo modo como um diálogo teatral.

${ }^{18}$ De acordo com Gossedge, na tradição galesa, Laqueu era filho do Rei Artur, mas na versão de Masefield seu pai é o Cavaleiro Lancelote (GOSSEDGE 2007: 225).

$$
\begin{gathered}
\text { TradTerm, São Paulo, v.38, fevereiro/2021, p. 91-115 } \\
\text { Número Especial - III JOTA } \\
\text { www.revistas.usp.br/tradterm }
\end{gathered}
$$


Save Lancelot perhaps at bitter whiles,

When the long pain was more than I could stand;

He being Arthur's cousin, was his heir

Till base-born Modred reacht us from the isles.

Thereafter was no comfort anywhere,

But Modred's plottings and my sister's wiles, And love that lit me ruining the land.
A não ser Lancelote talvez em tempos amargos, quando a longa dor era mais do que eu poderia suportar; ele sendo primo de Artur, era seu herdeiro até que Mórdred, vil de nascença, alcançou-nos vindo das ilhas. Depois, não houve conforto em lugar algum, salvo o fracasso das conspirações de Mórdred e os ardis de minha irmã, e o amor que me iluminava e destruía a terra.

\section{LANCELOT:}

I, who am Lancelot, the son of Ban, King Arthur's cousin, dealt the land the blow From which the griefs began.

I, who loved Gwenivere, as all men know, Was primal cause that brought the kingdom low, For all was peace until that quarrel fell; Thereafter red destruction followed fast. The gates of hell Hedge every daily track by which men go; My loving flung them open as I passt.

\section{LANCELOTE:}

Eu, que sou Lancelote, filho de Ban, primo do Rei Artur, desferi o golpe que foi a origem dos pesares da terra. Eu, que amei Ginevra, como todos os homens sabem, fui a causa primordial que abateu o reino, pois tudo estava em paz até aquela disputa surgir; consequentemente a destruição escarlate seguiu-se veloz. Os portões para o inferno cercam todo caminho diário que os homens seguem; meu amor os escancarou quando eu passei.

\begin{tabular}{|l|l}
\hline \multicolumn{1}{|c|}{ GWENIVACH: } & \multicolumn{1}{c}{ Gineva: } \\
I, who am Princess Gwenivach the Fair, & Eu, que sou a Princesa Gineva, a \\
Compasst the kingdom's ruin by my hate, & Formosa, causei a ruína do reino com \\
The poisonous hate I bare & o meu ódio, o tóxico ódio que eu \\
For Gwenivere, my sister, Arthur's mate. & carrego por Ginevra, minha irmã, \\
My mind was as a murderer in wait & companheira de Artur. Minha mente \\
Behind a door, on tiptoe, with a knife, & era um assassino à espera, atrás de \\
Ready to stab her at the slightest chance, & uma porta, na ponta dos pés, com \\
Stab to the life. & uma faca, pronta para apunhalá-la \\
I stabbed her to the heart in her estate; & numa mínima oportunidade, \\
Disaster was my blow's inheritance. & assassiná-la. Eu a apunhalei no \\
& coração em sua propriedade; a \\
& desgraça foi a herança de meu golpe.
\end{tabular}

MODRED:

Not you, with your begettings, father mine; Not you, my red-gold Queen, adultress proud; Not you, Sir Lancelot, whom none could beat; Not you, my princess sweet;

Not one of all you waters was worth wine. Mine was the hand that smote this royal seat, Mine was the moving darkness that made cloud; You were but nerves; I Modred was the spine.

\section{MÓRDRED}

Não foste tu, com tuas concepções, meu pai; não foste tu, minha Rainha acobreada, altiva adúltera; não foste tu, Sir Lancelote, aquele que ninguém poderia derrotar; não foste tu, minha doce princesa; nenhuma de vossas águas se equiparavam a vinho. Foi minha a mão que golpeou o trono real, foi minha a movente escuridão

TradTerm, São Paulo, v.38, fevereiro/2021, p. 91-115

Número Especial - III JOTA www.revistas.usp.br/tradterm 
que trouxe desgraça; vós não passastes de nervos; eu Mórdred era a espinha dorsal.

You were poor puppets in a master's game;

I, Modred, was the cause of what befell.

I, Modred, Arthur's bastard, schemed and planned; I, with my single hand,

Gave but a touch, and, lo, the troubles came;

And royalty was ended in the land.

When shut from Heaven, devils create hell:

Those who ignore this shall repent the same.
Vós fostes meros fantoches em um jogo de mestre; eu, Mórdred, fui a causa do que ocorreu. Eu, Mórdred, o bastardo de Artur, conspirei e planejei; eu, só com a minha mão, dei apenas um toque, e, eis que os problemas vieram; e a realeza chegou ao fim na terra. Quando excluídos do Paraíso, os demônios infernizam: aqueles que ignorarem isto devem se arrepender decerto.
You were at peace, King Arthur (cuckold's peace); Your queen had both her lover and her son; And I, your bastard by your aunt, was far, Where Orkney tide-rips jar. Your Kingdom was all golden with increase. Then your son's killing happened: Modred's star Rose; I was heir, my bastardy was done; Or (with more truth) I swore to make it cease.
Tu estavas em paz, Rei Artur (paz de marido enganado); tua rainha tinha tanto o amante quanto o filho dela; e eu, teu bastardo por parte de tua tia, estava longe, onde se quebra estrondosa a maré das Órcadas. Teu Reino estava tão próspero com o progresso. Então o assassinato de teu filho aconteceu: a estrela de Mórdred ascendeu; eu era herdeiro, minha bastardia estava acabada; ou (na verdade) eu jurei que faria com que ela acabasse.
But coming to your court with double claim (As son and nephew) to the British crown, You and the Queen named Lancelot the heir: A brave man and a rare;

Your cousin King, the cuckoo ${ }^{19}$ to your dame, Whom nobody opposed till I was there. But I opposed, until I tumbled down The realm to ruin and the Queen to shame.
Contudo, vindo à tua corte com dupla reivindicação (como filho e como sobrinho) da coroa Britânica, tu e a Rainha nomeastes Lancelote como herdeiro: um homem corajoso e raro; teu primo Rei, que colocou chifres na tua cabeça, a quem ninguém se opunha até eu aparecer. Entretanto, eu me opus, até eu derrubar o reino em direção à ruína e a Rainha à vergonha.

19 Pássaro cinza que põe os ovos nos ninhos de outros pássaros. O Vilão Mórdred refere-se ao fato de que o Cavaleiro Lancelote teve um filho com a Rainha Ginevra que todos acreditavam ser do Rei Artur, tornando-o um 'chifrudo' por assim dizer. Cf. CUCKOO <https://dictionary.cambridge.org/dictionary/english/cuckoo>. Acesso em 05 jan. 2021. Já no português, de acordo com o Dicionário Aulete Digital, uma das acepções de cuco, pode ser "Marido cuja mulher the é infiel". Seu sentido é lusitano e de antigo tabu. Cf. CUCO 1 (Acepção 4) <http://www. aulete.com.br/cuco>. Acesso em 10 maio 2021.

TradTerm, São Paulo, v.38, fevereiro/2021, p. 91-115

Número Especial - III JOTA www.revistas.usp.br/tradterm 
And I, your younger sister, whom you slighted, Loved Modred from the first and took his part. That made the milk of your sweet fortune sour. I told you in the tower,

The green-hung tower, by the sunset lighted, Sunset and moonrise falling the same hour; Then I declared how Modred had my heart, That we were lovers, that our troths were plighted.
E eu, tua irmã mais nova, a quem tu desprezavas, amei Mórdred desde o princípio e fiquei ao seu lado. Isso fez o leite da tua doce fortuna azedar. Eu te disse na torre, a torre esverdeada, iluminada pelo ocaso, ocaso e nascer da lua ao mesmo tempo; depois, eu declarei como Mórdred tinha meu coração, que nós éramos amantes, que juramos fidelidade um ao outro.
You could have won our love, had you been wise; Then, when, as lovers, we confesst ${ }^{20}$ and pled Together with you for a lasting truce.

No blood would have been shed, April and June had had their natural use, And autumn come with brimming granaries. But no; you gave refusal and abuse; Therefore I smote your lips so harlot-red... The joy of that one buffet never dies.

\section{Tu poderias ter conquistado nosso amor, se tivesses sido esperta; então, como amantes, nós confessamos e argumentamos juntos contigo a fim de proporcionar uma longa trégua. Nenhum sangue teria sido derramado, abril e junho tinham tido sua natural utilidade, e o outono viria com os armazéns repletos. Mas não, tu ofereceste rejeição e ofensa; portanto eu feri teus lábios tão vermelhos como os da prostituta... a alegria desse bofete em particular nunca morre.}

I see you at this moment, standing still, White, by the window in that green-hung tower, Just as I struck you, while your great eyes gleamed.

Till then, I had but seemed...

My striking showed you how I longed to kill. $\mathrm{O}$ through what years of insult had I dreamed For that one stroke in the avenging hour! The devil of my hatred had her will: God pity me, fate fell not as I deemed."
Eu te vejo neste momento, imobilizada, pálida, perto da janela naquela torre esverdeada, enquanto eu te golpeei, quando teus grandes olhos cintilavam. Até ali, eu só fingia... meu golpe te mostrou como eu ansiava matar. Ó, por quantos anos de insulto eu sonhei com aquele golpe na hora da vingança! O demônio do meu ódio conseguiu o que queria: Que Deus tenha misericórdia de mim, o destino não sucedeu como eu cria.
So, with lamenting of the ancient woe

They told their playings in the tragic plot, Until their eyes were bright:

The red-gold beauty wept for Lancelot. Then the church belfries in the vale below Chimed the first hour of the year's decay, And Arthur spoke: Our hour glides away; Gone is the dim perfection of night,
Assim, com lamentação da antiga angústia, eles contaram seus feitos na trágica trama, até que seus olhos ficaram brilhantes: a beldade acobreada chorou por Lancelote. Em seguida, os campanários da igreja no vale abaixo badalaram a primeira hora do declínio do ano, e Artur falou: -

${ }^{20} \mathrm{O}$ arcaísmo aqui do verbo 'confesst', por exemplo, é compensado pela forma arcaica el-rei.

TradTerm, São Paulo, v.38, fevereiro/2021, p. 91-115

Número Especial - III JOTA

www.revistas.usp.br/tradterm 


\begin{tabular}{|l|l|}
\hline Not yet does any trumpet bid us go. & $\begin{array}{l}\text { Nossa hora se esgota; foi-se a turva } \\
\text { perfeição da noite, por ora, nenhuma } \\
\text { trompa ordenou que fôssemos. }\end{array}$ \\
\hline
\end{tabular}

But when the trumpet summons, we will rise, We, who are fibres of the country's soul, We will take horse and come To purge the blot and make the broken whole; And make a green abundance seem more wise, And build the lasting beauty left unbuilt Because of all the follies of our guilt. But now the belfry chimes us to be dumb, Colour is coming in the eastern skies."
Mas quando a trompa chamar, nós ressurgiremos, nós, que somos fibras da alma do país, nós tomaremos cavalos e viremos purificar a mácula e tornar inteiro o que foi quebrado; e fazer a abundância do verde parecer mais prudente, e construir a beleza duradoura deixada por construir por causa de todas as loucuras da nossa culpa. Mas agora o campanário badala para nos tornar mudos, a cor está chegando nos céus orientais.
Then as those figures lapsed again to stone, The horses stamped, the cock his challenge flung, The gold-wrought banners stirred, The air was trembling from the belfry's tongue. Above those forms the Helper stood alone, Shining with hope. But now the dew was falling, In unseen downland roosts the cocks were calling, And dogrose petals shaken by a bird Droppen from the blossomed briar and were strown.
Depois, à medida que as figuras passaram novamente a ser pedra, os cavalos bateram seus cascos, o galo emitiu seu grito de alerta, os estandartes ornados em ouro se agitaram, o ar estremeceu com o badalo do campanário. Acima daquelas formas, o Ajudante ficou sozinho, radiante de esperança. Mas agora o orvalho caía, em poleiros escondidos no vale, os galos cantavam, e pétalas de rosa canina sacudidas por um pássaro, derrubadas do florido arbusto eram disseminadas.

TradTerm, São Paulo, v.38, fevereiro/2021, p. 91-115

Número Especial - III JOTA

www.revistas.usp.br/tradterm 


\section{Referências}

AULETE, C. Aulete Digital - Dicionário contemporâneo da língua portuguesa: Dicionário Caldas Aulete, vs online, acesso feito em 21 jan 2021.

Bevan, J. O. The Towns of Roman Britain. 2010. Disponível em https: / / www.gutenberg.org/files/33059/33059-h/33059-h.htm. Acesso em: 10 jan. 2021.

CAMBRIDGe UnIVERSITY Press. Cambridge online dictionary, Cambridge dictionary online. Disponível em https://dictionary.cambridge.org/pt/>. Acesso em: 10 jan 2021.

Collins, M. The Arthurian Court List in Culhwch and Olwen. In: LuPACK, A.; LuPACK, B. T. (Ed.) The Camelot Project. Rocherster: The Robbins Library, University of Rochester. 1995. Disponível em https://d.lib.rochester.edu/camelot/text/collins-arthurian-court-listin-culhwch-and-olwen\#190. Acesso em 10 jan. 2021.

DodDS, D. L. Arthurian Poets: John Masefield. Rochester: The Boydell Press, Woodbridge. 1994.

GONÇALVES, D. F. O tradutor imaginário: Pseudotradução - um encontro secular entre tradução e literatura. 2015. 262 f. Tese (Doutorado) Departamento de Letras Modernas, Faculdade de Filosofia, Letras e Ciências Humanas, Universidade de São Paulo, 2015.

GOSSEDGE, R. 'The Old Order Changeth': Arthurian literary production from Tennyson to White. 2007. 428 p. Ph. D. thesis (English Literature) Cardiff University.

LUKÁCS, G. “O romance como epopéia burguesa”, in CHASIN, J. (org.), Trad. a partir da edição italiana (Einaudi, 1976) e francesa (Editions Sociales, 1974) Zini Antunes Ensaios Ad Hominem - Tomo II - Música e Literatura. Santo André: Estudos e edições Ad Hominem, 1999.

MARQueS, R. E-Dicionário de Termos Literários. Carlos Ceia. Disponível em <https://edtl.fcsh.unl.pt/encyclopedia/ricardomarques/>. Acesso em: 10 jan. 2021.

MASEFIELD, J. Midsummer night and other tales in verse. Londres: W. Heinemann. 1928.

Megale, H. (Org.). A demanda do Santo Graal. São Paulo: Companhia das Letras, 2008.

MERRIAM-WEBSter DictionaRY. (C) 2020 Merriam-Webster, Incorporated. Disponível em <https://www.merriam-webster.com/>. Acesso em 10 jan. 2021.

TradTerm, São Paulo, v.38, fevereiro/2021, p. 91-115

Número Especial - III JOTA

www.revistas.usp.br/tradterm 
Michaelis. Moderno Dicionário de Inglês \& Português. Disponível em: $<$ https://michaelis.uol.com.br/moderno-ingles/>. Acesso em 10 jan. 2021.

Monmouth, G. Historia Regum Britanniae. Ontario: Cambridge. 1999.

Rosenfeld, A. O teatro épico. São Paulo: Perspectiva, 1986.

ShAKESPEARE, W. Sonho de uma noite de verão. Tradução Rafael Raffaelli. Florianópolis: Ed. Da UFSC, 2016. 199p.

TheFreEDICTIONARY. American Heritage ${ }^{\circledR}$ Dictionary of the English Language, Fifth Edition. Copyright $\odot 2016$ by Houghton Mifflin Harcourt Publishing Company. Published by Houghton Mifflin Harcourt Publishing Company. Disponível em: <www.thefreedictionary.com>. Acesso em 10 jan. 2021.

YATES. R. J. John Masefield. In: War Poets Association. Disponível em <http://www. warpoets.org/conflicts/great-war/john-masefield-18781967/>. Acesso em 10 jan. 2021.

ZIERER, A. Damas e cavaleiros n' A Demanda do Santo Graal. Revista Graphos, v. 15, n. 1, 30 jun. 2013.

Recebido em: 15/03/2020

Aceito em: 22/09/2020

Publicado em fevereiro de 2021

TradTerm, São Paulo, v.38, fevereiro/2021, p. 91-115

Número Especial - III JOTA

www.revistas.usp.br/tradterm 